\title{
RECUPERAÇÃO DA ESCÓRIA DO FORNO DE REDUÇÃO DO MINÉRIO DE NÍQUEL PARA UTILIZAÇÃO COMO FERTILIZANTE
}

\author{
M. M. SILVA ${ }^{1}$, F. A. SAFATLE ${ }^{1}$, H. S. PEREIRA ${ }^{2}$, K. D. OLIVEIRA ${ }^{3}$ e \\ C. N. ÁVILA-NETO ${ }^{1}$ \\ ${ }^{1}$ Universidade Federal de Uberlândia, Faculdade de Engenharia Química \\ ${ }^{2}$ Universidade Federal de Uberlândia, Instituto de Ciências Agrárias \\ ${ }^{3}$ ESAMC Uberlândia, Faculdade de Engenharia \\ E-mail para contato: avilaneto@ufu.br
}

\begin{abstract}
RESUMO - Atualmente, o reaproveitamento da escória gerada durante o processamento de metais consiste em um dos grandes desafios das indústrias metalúrgicas extrativas. Nesse contexto, este trabalho apresenta uma perspectiva sustentável para tratamento da escória gerada durante a produção de liga metálica ferro-níquel, com o intuito de solubilizar o silício para a posterior utilização como fertilizante para as plantas. Para isso, foi realizada a caracterização da amostra por Fluorescência de Raios X e Difração de Raios X. Posteriormente, foram realizados testes de solubilidade do silício utilizando calcinação a $900{ }^{\circ} \mathrm{C}$ juntamente com carbonato de cálcio. Os resultados desmontaram que o procedimento não foi suficiente para solubilizar o Si presente na escória.
\end{abstract}

\section{INTRODUÇÃO}

A utilização de rejeitos como matéria-prima permite a minimização do impacto ambiental e posterior inserção no ciclo produtivo industrial de forma sustentável. Sendo assim, torna-se essencial o estudo da utilização de escorias geradas nesses processos, de maneira a se aproveitar, efetivamente, esses resíduos.

Especificamente na indústria metalúrgica de produção de liga ferro-níquel são geradas aproximadamente de 15 a 20 toneladas de escória para cada tonelada de níquel produzido segundo Lima e Zampieron (2009). A escória proveniente desse processo é estocada em pátios presentes na mineradora tornando-se um passivo ambiental. Além disso, há uma grande quantidade de silício presente na escória, elemento benéfico e importante para as plantas.

O silício é absorvido pela planta na forma de acido monossilícico $\left(\mathrm{H}_{4} \mathrm{SiO}_{4}\right)$ juntamente com a água (fluxo de massa) se acumula como ácido silícico polimerizado (sílica amorfa) principalmente nas áreas de máxima transpiração. Um número grande de materiais tem sido utilizado como fonte de Si para as plantas: escórias de siderurgia, wollastonita, subprodutos da produção de fósforo elementar, silicato de cálcio, silicato de sódio, cimento, termofosfato, silicato de magnésio e silicato de potássio. Neste trabalho foram utilizados procedimentos de caracterização para obter informações sobre a escória e realizados testes de solubilidade, com o objetivo de solubilizar silício. 


\section{METODOLOGIA}

\subsection{Calcinação}

A calcinação foi realizada para a verificação da alteração de massa com o aumento da temperatura. Para isso, a amostra foi pesada antes e após a calcinação. O procedimento foi realizado com $3 \mathrm{~g}$ de escória, os quais foram colocados em um cadinho e, posteriormente, inseridos na mufla à temperatura ambiente. Em seguida, foram aquecidos até a temperatura final e mantidos por $4 \mathrm{~h}$ utilizando uma rampa de aquecimento de $5^{\circ} \mathrm{C} \min ^{-1}$.

\subsection{Fluorescência de Raios $X$}

Utilizou-se a Fluorescência de Raios X (FRX) com o intuito de caracterizar a amostra quantitativamente em relação aos elementos presentes. Para tanto, foi macerado $7,2 \mathrm{~g}$ de escória, misturou-se com 0,8 g de cera PXR-200 e, então, a mistura foi prensada a $200 \mathrm{kPa}$ e levada ao equipamento Bruker S8 TIGER, no qual foi analisada.

\subsection{Difração de Raios $X$}

A Difração de Raios X (DRX) foi utilizada para caracterização qualitativa da amostra e fornece como resultado sua estrutura cristalina. Nesse processo, as amostras foram adicionadas ao equipamento Shimadzu XRD - $6000 \mathrm{com}$ radiação $\mathrm{Cu} \mathrm{K} \alpha(\lambda=1,54056 \AA)$ e varridas de $5^{\circ}$ a $85^{\circ} \mathrm{com}$ taxa de $1,2^{\circ} \mathrm{min}^{-1}$. Essa etapa foi realizada em dois momentos: na obtenção da escória a partir do processo industrial e após os tratamentos térmicos (calcinação). Para a identificação da formação das estruturas presentes na escória, foi utilizado o software SearchMatch e os difratogramas padrões da base de dados ICSD ("Inorganic Crystal Structure Database").

\subsection{Calcinação com Carbonato de Cálcio}

Foi utilizada a calcinação com carbonato de cálcio $\left(\mathrm{CaCO}_{3}\right)$ com o objetivo de solubilizar o silício presente na escória utilizando as Eqs. 1 e 2 como modelo. Esse procedimento foi realizado com o uso de uma rampa de aquecimento de $10^{\circ} \mathrm{C} \mathrm{min}{ }^{-1}$ a partir da temperatura ambiente até a temperatura de $900{ }^{\circ} \mathrm{C}$, que se manteve constante por tempos variados, além de se variar a quantidade de carbonato de cálcio utilizado. As informações contendo o planejamento utilizado nesse procedimento podem ser encontradas na Tabela 1.

$$
\begin{aligned}
& \mathrm{CaCO}_{3} \rightarrow \mathrm{CaO}+\mathrm{CO}_{2} \\
& \mathrm{SiO}_{2}+\mathrm{CaO} \rightarrow \mathrm{CaSiO}_{3}
\end{aligned}
$$

Com esse procedimento, espera-se que seja formado silicato de cálcio que, ao entrar em contato com água, produz ácido monossilícico $\left(\mathrm{H}_{4} \mathrm{SiO}_{4}\right)$, o qual consiste na forma em que a planta absorve o silício, de acordo com as Eqs. 3-5.

$$
\begin{aligned}
& \mathrm{CaSiO}_{3}+\mathrm{H}_{2} \mathrm{O} \rightarrow \mathrm{Ca}^{2+}+\mathrm{SiO}_{3}{ }^{2-} \\
& \mathrm{SiO}_{3}{ }^{2-}+2 \mathrm{H}^{+} \rightarrow \mathrm{H}_{2} \mathrm{SiO}_{3}
\end{aligned}
$$




$$
\mathrm{H}_{2} \mathrm{SiO}_{3}+\mathrm{H}_{2} \mathrm{O} \rightarrow \mathrm{H}_{4} \mathrm{SiO}_{4}
$$

Tabela 1 - Planejamento experimental referente à calcinação da escória com carbonato de cálcio.

\begin{tabular}{|c|c|c|}
\hline Massa de escória (g) & Massa de $\mathrm{CaCO}_{3}(\mathrm{~g})$ & Tempo (min) \\
\hline \multirow{3}{*}{3} & \multirow{3}{*}{1,01} & 30 \\
\hline & & 60 \\
\hline & & 120 \\
\hline \multirow{3}{*}{3} & \multirow{3}{*}{2,01} & 30 \\
\hline & & 60 \\
\hline & & 120 \\
\hline \multirow{3}{*}{3} & \multirow{3}{*}{3,02} & 30 \\
\hline & & 60 \\
\hline & & 120 \\
\hline
\end{tabular}

\subsection{Análise de silício total e silício solúvel}

O procedimento realizado nesta etapa do trabalho foi a analise de silício total e silício solúvel com as amostras de escoria calcinada com carbonato de cálcio de acordo com o procedimento descrito no trabalho de Buck (2010).

\subsection{Difração de Raios X pós calcinação com Carbonato de Cálcio}

Após a realização das calcinações envolvendo a escória e o carbonato de cálcio(CaCO3), foi realizada novamente a difração de raios $\mathrm{X}(\mathrm{DRX})$, com o intuito de averiguar quais foram as estruturas formadas após a calcinação.

\section{RESULTADOS}

\subsection{FRX da escória não calcinada}

O resultado do FRX contido na Tabela 2 demonstra que a escória não calcinada possui quantidade relevante de silício ( $\mathrm{Si}$ ), assim como era esperado.

Tabela 2 - Concentração das substâncias presentes na amostra.

\begin{tabular}{ccccccccccccccc}
\hline Óxido & $\mathrm{SiO}_{2}$ & $\mathrm{MgO}$ & $\mathrm{Fe}_{2} \mathrm{O}_{3}$ & $\mathrm{Al}_{2} \mathrm{O}_{3}$ & $\mathrm{Cr}_{2} \mathrm{O}_{3}$ & $\mathbf{C a O}$ & $\mathrm{MnO}$ & $\mathrm{Na}_{2} \mathrm{O}$ & $\mathrm{K}_{2} \mathrm{O}$ & $\mathrm{NiO}$ & $\mathrm{TiO}_{2}$ & $\mathrm{SO}_{3}$ & $\mathrm{ZnO}$ & $\mathrm{BaO}$ \\
\hline \multirow{2}{*}{)} & 40,00 & 21,41 & 13,58 & 3,02 & 1,09 & 0,47 & 0,33 & 0,15 & 0,11 & 0,08 & 0,08 & 0,06 & 0,03 & 0,03
\end{tabular}

\subsection{Calcinação da escória}

A calcinação foi realizada para averiguar como a escória se comporta com o aumento da temperatura. Assim, a partir dos dados obtidos, foi construída a Tabela 3, que mostra a perda de massa da escória quando esta foi submetida a várias temperaturas de calcinação. É possível 
observar um aumento de massa a partir de $500{ }^{\circ} \mathrm{C}$. Esse aumento pode estar ligado à reabsorção de água após o contato da amostra calcinada com o ar úmido, o que revela seu caráter higroscópico.

Tabela 3 - Resultado obtido com a calcinação.

\begin{tabular}{ccccc}
\hline $\boldsymbol{T}\left({ }^{\circ} \mathbf{C}\right)$ & Massa inicial $(\mathbf{g})$ & Massa final $(\mathbf{g})$ & Perda de massa $(\mathbf{g})$ & Porcentagem $(\boldsymbol{\%})$ \\
\hline $\mathbf{2 0 0}$ & 3,0000 & 2,9905 & 0,0095 & 99,68 \\
\hline $\mathbf{3 0 0}$ & 2,9999 & 2,9982 & 0,0017 & 99,94 \\
\hline $\mathbf{4 0 0}$ & 3,0002 & 2,9839 & 0,0163 & 99,46 \\
\hline $\mathbf{5 0 0}$ & 3,0005 & 2,9894 & 0,0111 & 99,63 \\
\hline $\mathbf{6 0 0}$ & 3,0005 & 3,0032 & $-0,0027$ & 100,09 \\
\hline $\mathbf{7 0 0}$ & 3,0009 & 3,0129 & $-0,012$ & 100,4 \\
\hline $\mathbf{8 0 0}$ & 3,0006 & 3,0086 & $-0,008$ & 100,27 \\
\hline $\mathbf{9 0 0}$ & 3,0006 & 3,0226 & $-0,022$ & 100,73 \\
\hline $\mathbf{1 0 0 0}$ & 3,0003 & 3,0262 & $-0,0259$ & 100,86 \\
\hline
\end{tabular}

A Fig. 1 apresenta os difratogramas de raios $X$ obtidos com a escória não calcinada e também da escória calcinada em várias temperaturas. Além disso, está presente na figura o difratograma de raios $\mathrm{X}$ referente ao silicato de magnésio $\left(\mathrm{MgSiO}_{3}\right)$ e ao óxido de ferro $\left(\mathrm{Fe}_{3} \mathrm{O}_{4}\right)$.

Figura 1 - Difratogramas de raios X da escória não calcinada, da escória calcinada em várias temperaturas e das referências $\mathrm{MgSiO}_{3} \mathrm{e} \mathrm{Fe}_{3} \mathrm{O}_{4}$.

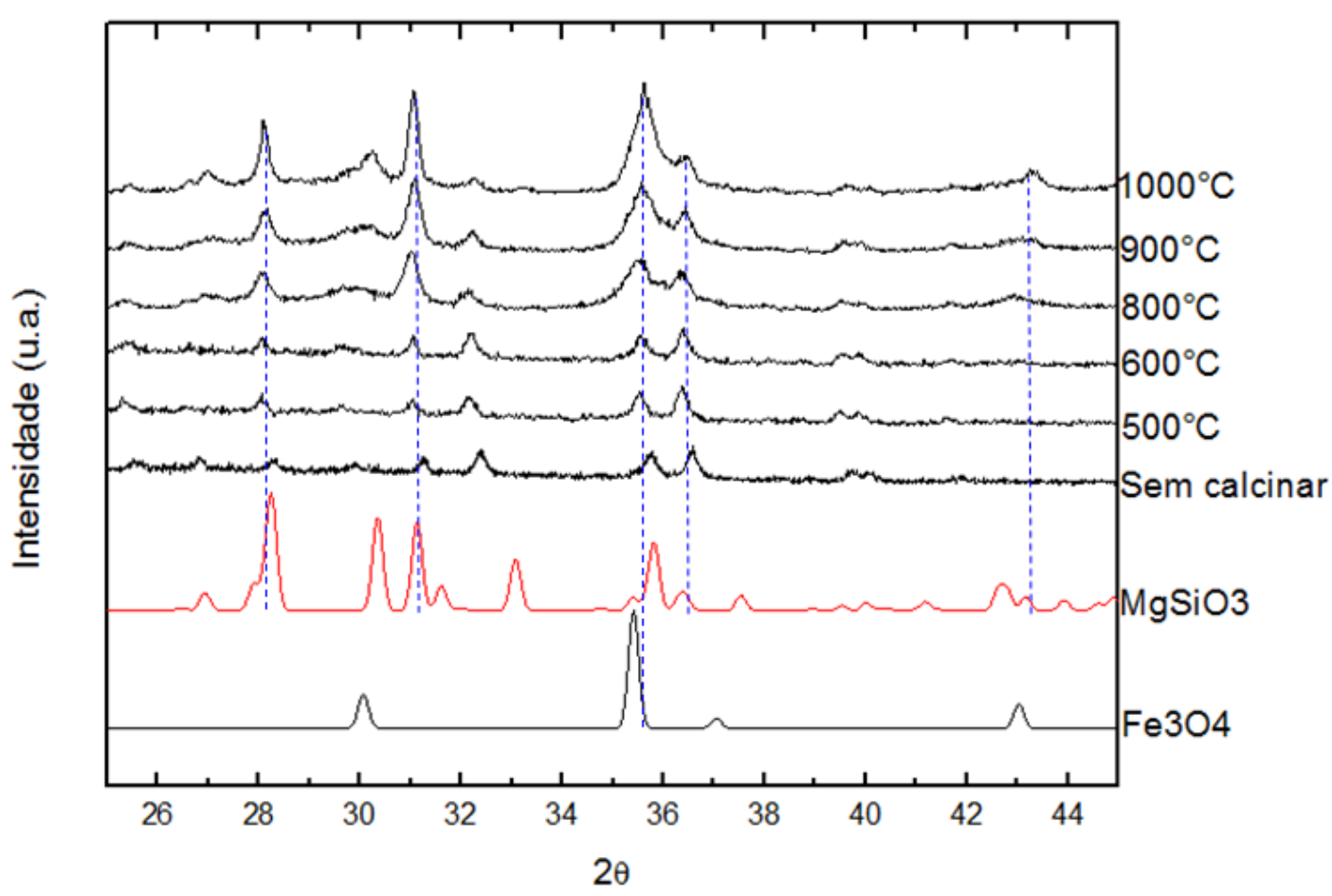

\subsection{Análise de silício total e silício solúvel}


A Tabela 4 mostra os resultados de solubilidade do Si após o procedimento de calcinação com $\mathrm{CaCO}_{3}$. Ao analisar a Tabela 4, é possível verificar que a escória realmente possui uma grande quantidade de silício total, porém o método proposto para solubilizar a silício não foi suficientemente eficaz, visto que a quantidade de silício solúvel foi desprezível.

Tabela 4 - Concentração das substâncias presentes na amostra.

\begin{tabular}{ccccc}
\hline Amostra & Massa de CaCO3 $\mathbf{~ ( g ) ~}$ & Tempo (min) & Si total (\%) & Si solúvel (\%) \\
\hline $\mathbf{1}$ & 1,01 & 30 & 19,04 & 1,67 \\
\hline $\mathbf{2}$ & 2,01 & 30 & 16,84 & 0,45 \\
$\mathbf{3}$ & 3,01 & 30 & 14,46 & 0,30 \\
$\mathbf{4}$ & 1,01 & 60 & 20,44 & 1,19 \\
\hline $\mathbf{5}$ & 2,01 & 60 & 16,4 & 0,79 \\
\hline $\mathbf{6}$ & 3,01 & 60 & 15,07 & 0,62 \\
\hline $\mathbf{7}$ & 1,01 & 120 & 20,16 & 1,21 \\
\hline $\mathbf{8}$ & 2,01 & 120 & 17,39 & 0,64 \\
\hline $\mathbf{9}$ & 3,01 & 120 & 15,6 & 0,51 \\
\hline $\mathbf{1 0}$ & 1,01 & 0 & 18,76 & 2,29 \\
\hline $\mathbf{1 1}$ & 2,01 & 0 & 15,16 & 1,94 \\
\hline $\mathbf{1 2}$ & 3,01 & 0 & 12,91 & 0,79 \\
\hline
\end{tabular}

\subsection{Difração de Raios $X$ pós calcinação}

A figura 2 apresenta os difratogramas de algumas amostras que foram calcinadas juntamente com o carbonato de cálcio $\left(\mathrm{CaCO}_{3}\right)$. A partir delas, foi possível concluir que houve a formação de hidróxido de cálcio $\left(\mathrm{Ca}(\mathrm{OH})_{2}\right)$, com os picos padrões destacados na figura com a letra "a", em praticamente todas as amostras com exceção das amostras 10 e 12 em que foi identificado somente o carbonato de cálcio $\left(\mathrm{CaCO}_{3}\right)$ representado na figura com a letra "c". Além disso, nas amostra 3,6 e 9 foram identificados picos referentes ao óxido de cálcio $(\mathrm{CaO})$ representados na figura com a letra "b". 
Figura 2 - Difratogramas de raios X da escória calcinada juntamente com o carbonato de cálcio

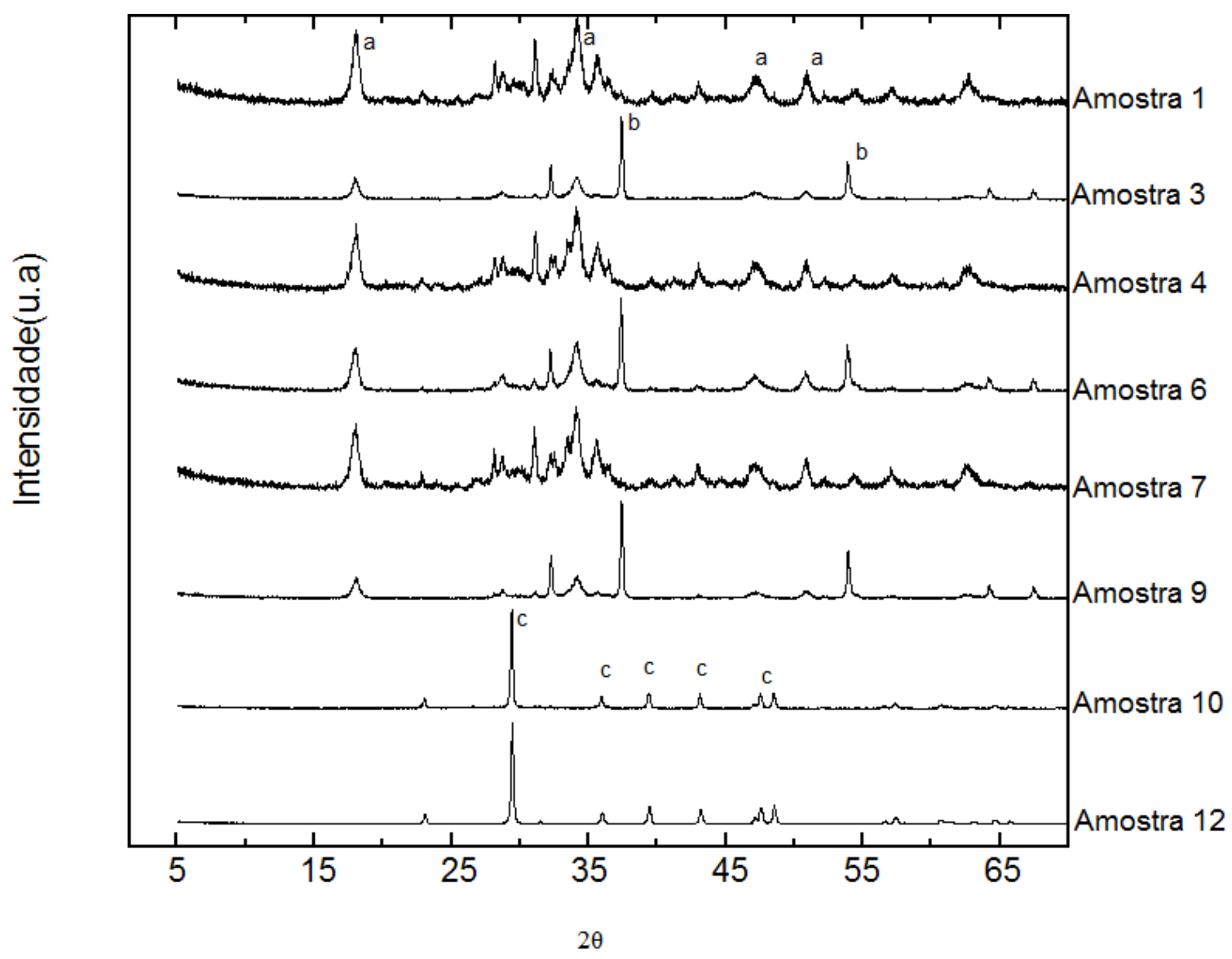

\section{CONSIDERAÇÕES FINAIS}

A partir dos resultados obtidos, foi possível caracterizar a amostra de maneira quantitativa e qualitativa. Além disso, houve a confirmação de que a escória, que é um passivo ambiental, pode ser utilizada como uma grande fonte de silício. Entretanto, os resultados obtidos referentes à solubilidade deste silício não foram satisfatórios. A próxima etapa deste trabalho compreende um estudo mais detalhado sobre uma maneira de solubilizar o silício e, posteriormente à solubilização, será feito o teste de campo nas plantas com o produto final.

\section{REFERÊNCIAS BIBLIOGRÁFICAS}

BUCK,G.B, Metodologia para determinação de silício em fertilizantes,2010.

LIMA,R.L.Avaliação da escória de níquel como possível matéria prima para pigmento cerâmico,2009. 